American Journal of Environmental Sciences 7 (3): 207-211, 2011

ISSN 1553-345X

(C) 2011 Science Publications

\title{
Feasibility Study and Performance Analysis of Solar Assisted Desiccant Cooling Technology in Hot and Humid Climate
}

\author{
Arfidian Rachman, Kamaruzzaman Sopian, Sohif Mat and Muhammad Yahya \\ Solar Energy Research Institute, University Kebangsaan Malaysia, \\ 43600 Bangi, Selangor Darul Ehsan, Malaysia
}

\begin{abstract}
Problem statement: New approaches to space conditioning of buildings are to resolve environmental, economic and regulatory issues. One of the alternative systems that brought to agenda is the desiccant cooling systems, which may provide important advantages in solving air conditioning problems. Approach: The performance analysis of desiccant cooling with solar energy are analyzed. The system was designed, constructed and tested in National University of Malaysia. This system consist of a desiccant wheel, heat recovery wheel, evaporative cooler, fan, solar collector (vacuum tube) and electric heater unit. Results: As the key/design parameters, the rotation speed $12 \mathrm{rph}$ and the ratio area of regeneration temperature from $50-120^{\circ} \mathrm{C}$ and the thermodynamics coefficient of performance obtained was 0.6 conditions. Conclusion: The results confirmed the potential use of the technology satisfactorily in hot and humid conditions.
\end{abstract}

Key words: Desiccant cooling, evaporative cooling, low energy cooling, Coefficient Of Performance (COP), desiccant wheel

\section{INTRODUCTION}

Solar assisted cooling is particularly attractive because it is clean, renewable and has a low cost and the cooling demand is in phase with availability of solar radiation. Solar radiation is mainly used as energy source, which is collected by common solar collectors, to re-concentrate the dilute desiccant solution; Charoensawan and Wannagosit (2010) and Ibrahim et al. (2009). The open cycle solar collector, on the other hand, utilizes not only the solar energy but also the unsaturated air as regeneration energy source; Rachman et al. (2010).

Feasibility study solar assisted desiccant coolingreview: Advantages of using desiccant cooling systems include the following: (1) very small electrical energy is consumed and the sources for the regenerating thermal energy can be diverse (i.e., solar energy);(2) a desiccant system is likely to eliminate or reduce the use of ozone depleting CFCs (depending on whether desiccant cooling is used in conjunction with evaporative coolers or vapor compression systems, respectively); (3) control of humidity can be achieved better than those cases employing vapor compression systems since sensible and latent cooling occur separately and, (4) improvement in indoor air quality is likely to occur because of the normally high ventilation and fresh air flow rates employed. Also, desiccant systems have the capability of removing airborne pollutants.
Desiccant cooling systems show great energy saving potential by using low-grade heat source, such as solar energy. A lot of study solar assisted desiccant cooling; Jain and Dhar (1995) investigated four cycles (the ventilation cycle, the recirculation cycle, the Dunkle cycle and the wet surface heat exchangers cycle) for various outdoor conditions (Dry-bulb temperature and wet bulb temperature) of many cities in India. The study was aimed at evaluating the influence of the effectiveness of heat exchangers and evaporative coolers on the cooling Coefficient Of Performance (COP) as well as on the air volumetric circulation rate in different climatic conditions. The authors found the Dunkle cycle to have better performance compared to recirculation and ventilation cycles in all climatic conditions. But the cycle using wet surface featured the best performance with respect to all the three other cycles investigated. Camargo and Ebinuma (2005) and Kairouani and Nehdi (2005) investigated the works using the desiccant technology are involved with adsorption refrigeration and desiccant air conditioning systems. Dammak et al. (2010) investigated parameters of a solar bubble pump for absorption-diffusion cooling systems. Ando and Kodama (2005) used 4-rotor desiccant cooling process equipped with a double stage dehumidification. Regeneration temperature around $70^{\circ} \mathrm{C}$ could produce a sufficient dehumidifying performance at high ambient humidity.

Corresponding Author: Arfidian Rachman, Solar Energy Research Institute, University Kebangsaan Malaysia, 43600 Bangi, Selangor, Malaysia Tel: +60 163141600 
The present article proposes solar air conditioning desiccant wheel system for application in Malaysia. Design specifications of such a system to operate in the hot and humid conditions of Bangi-Malaysia. The article also provides the findings of coefficient of performance desiccant cooling system.

\section{MATERIALS AND METHODS}

Figure1 show a desiccant cycle operates as follows: (1) is dehumidified in a desiccant wheel (2); it is then cooled in the heat recovery wheel (3) by the return cooled air before being further cooled in an evaporative process (4), finally, it is introduced into condition room. The operating sequence for the return air (5) is as follows: it is cooled to its saturation temperature by evaporative cooler (6) and then it cools the fresh air in the heat recovery wheel (7). It is then heated in the heat exchanger by solar collector or heater (8) and finally regenerates the desiccant wheel (9) by removing the humidity before exiting the system.

Figure 2 show the experimental setup used to investigate the desiccant cooling technology. The desiccant cooling units consist of a desiccant wheel, a heat recovery wheel, two evaporative cooler, blower and a regeneration heat exchanger (water to air).

The desiccant wheels are designed to operate with both a $50 \%$ area for reactivation and $50 \%$ for process (50/50 split). The diameter of the wheel is $250 \mathrm{~mm}$ and the width is $533 \mathrm{~mm}$ with the angular velocity of $8 \mathrm{rev}$ $\mathrm{h}^{-1}$ for a nominal air-flow rate of $6000 \mathrm{~m}^{3} \mathrm{~h}^{-1}$. The heat recovery wheel is an aluminum honeycomb structure. It rotates at $12 \mathrm{rev} \mathrm{min}^{-1}$. The diameter of the regenerator is $700 \mathrm{~mm}$ and its width is $700 \mathrm{~mm}$. The installed evaporative cooler max air flow $6000 \mathrm{~m}^{3} \mathrm{~h}^{-1}$. The electrical consumption of the motor is about $150 \mathrm{~W}$. The system mainly includes $12 \mathrm{~m}^{2}$ solar air collectors with temperature range of between 80 and $120^{\circ} \mathrm{C}$, feeding a storage tank of $1000 \mathrm{~L}$. In reality this storage capacity is over dimensioned since energy is needed to raise the tank's temperature the desired level for regeneration. However this storage volume was chosen to protect the collectors from overheating since the installation is used for experimental purpose only and yet is not operational every day thus high capacity is needed.

Theoritical analysis: Desiccant cooling units are heatdriven system sand the coefficient of performance is defined as:

$$
\mathrm{COP}=\frac{\mathrm{Q}_{\text {cool }}}{\mathrm{Q}_{\text {regen }}}=\frac{\mathrm{m}_{\mathrm{s}}\left(\mathrm{h}_{5}-\mathrm{h}_{4}\right)}{\mathrm{m}_{\mathrm{a}}\left(\mathrm{h}_{8}-\mathrm{h}_{7}\right)}
$$

Where:

$\mathrm{Q}_{\text {cool }}=$ Rate of heat removed from the cooled room

$\mathrm{Q}_{\text {regen }}=$ Rate of regeneration heat supplied to the unit

$\dot{\mathrm{m}}_{\mathrm{a}} \quad=$ Mass flow rate of air

$\mathrm{h} \quad=$ Enthalpy of moist air and the state numbers refer to Fig. 1 throughout this stud

Considering that the mass flow rates are equal in process and regeneration lines, the effectiveness of rotary regenerator may be expressed as:

$\varepsilon_{\mathrm{HRW}}=\frac{\mathrm{T}_{2}-\mathrm{T}_{3}}{\mathrm{~T}_{2}-\mathrm{T}_{6}}$

where, $\mathrm{T}$ is temperature of moist air. The effectiveness of desiccant wheel may be expressed in similar way:

$\varepsilon_{\mathrm{DW}}=\frac{\mathrm{T}_{2}-\mathrm{T}_{3}}{\mathrm{~T}_{2}-\mathrm{T}_{6}}$

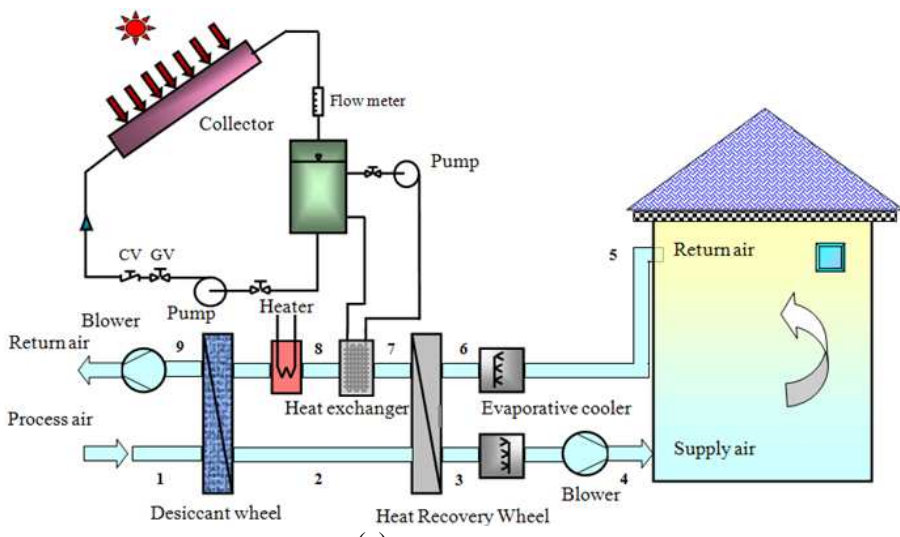

(a)

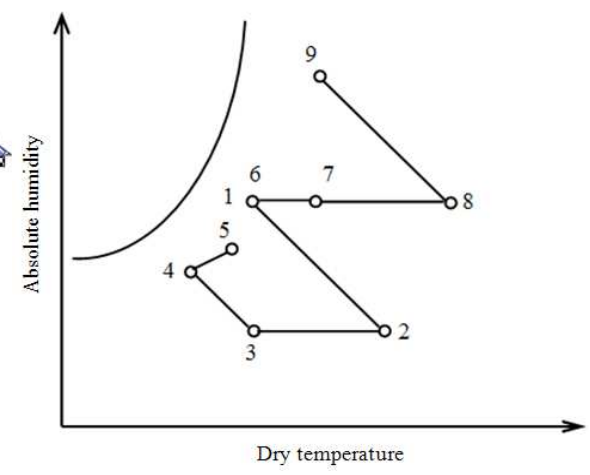

(b)

Fig. 1: Schematic diagram of solar assisted desiccant cooling system and representation on a psychrometric chart 


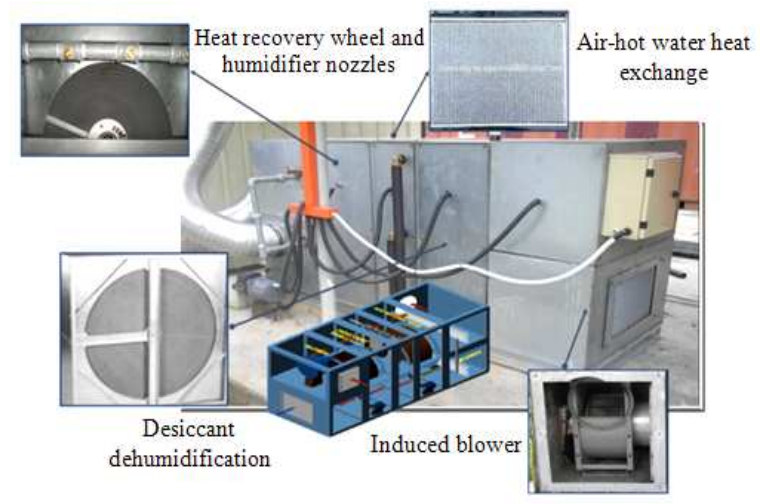

Fig. 2: Experimental solar assisted desiccant cooling installation

The effectiveness relations for the evaporative coolers are:

$\varepsilon_{\mathrm{EC}, 1}=\frac{\mathrm{T}_{3}-\mathrm{T}_{4}}{\mathrm{~T}_{3}-\mathrm{T}_{\mathrm{Wb} 3}}$

$\varepsilon_{\mathrm{EC}, 2}=\frac{\mathrm{T}_{5}-\mathrm{T}_{6}}{\mathrm{~T}_{5}-\mathrm{T}_{\mathrm{Wb} 5}}$

where, $\mathrm{T}_{\mathrm{Wb}}$ is wet-bulb temperature of moist air. Also, a mass balance on the two evaporative coolers gives:

$\dot{\mathrm{m}}_{\mathrm{w} 1}=\dot{\mathrm{m}}_{\mathrm{a}}\left(\mathrm{W}_{4}-\mathrm{W}_{3}\right)$

$\dot{\mathrm{m}}_{\mathrm{w} 2}=\dot{\mathrm{m}}_{\mathrm{a}}\left(\mathrm{W}_{6}-\mathrm{W}_{5}\right)$

where, $\dot{\mathrm{m}}_{\mathrm{w} 1}$ and $\dot{\mathrm{m}}_{\mathrm{w} 2}$ are the rates of moisture added to air in the evaporative coolers in the process and regeneration lines, respectively.

\section{RESULTS}

Figure 3 shows the effects of the ambient temperature and humidity ratio on the moisture removal. The ambient temperature and humidity affect the moisture removal greatly-the higher the moisture removal will be. The reason for this lies in the fact that the performance the rotary desiccant wheel is intimately with changes in ambient temperature. The increase of moisture removal, which can be attributed to that less latent heat loads is removed by the system.

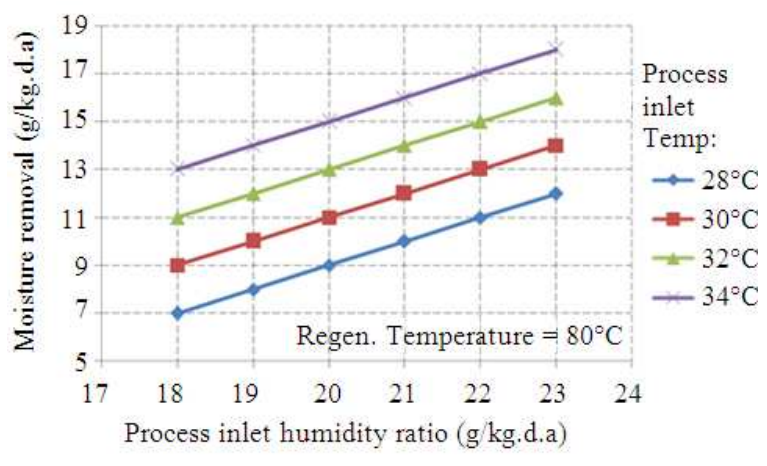

Fig. 3: Desiccant wheel moisture-removal performance

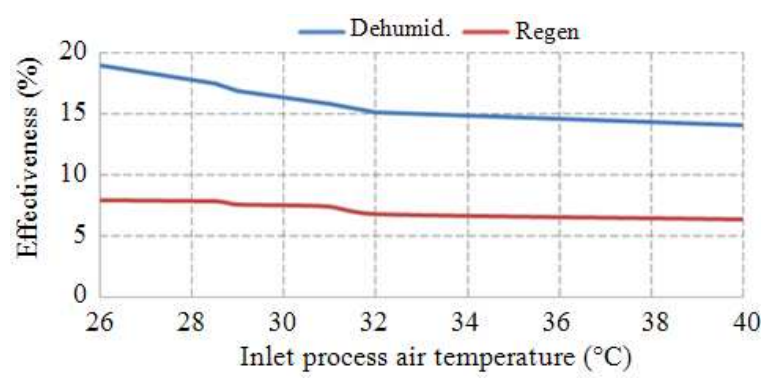

Fig. 4: Variation of desiccant wheel efficiencies in hot humid conditions

According to our measurements and given relations efficiency of the desiccant wheel in hot and humid condition have been presented in Fig. 4 which show its variations versus air temperature in hot and humid conditions. By increasing the inlet air temperature, dehumidification of the desiccant wheel decrease because of the better adsorption operation at low temperatures. Decrease in the adsorbed wheel humidity with assumption of constant regeneration heat leads to reduction in the regeneration and modified regeneration efficiency.

The second reasons are found in the regeneration and modified regeneration efficiencies, both of which are related to the amount of utilized regeneration heat for the desorption process. Respecting to the energy balance of regeneration side, some heat is used to remove water content of the adsorbent and the remaining exits in the regeneration process with outlet stream and causes heating of the desiccant wheel.

Figure 5, shows the efficiency of the heat recovery wheel at various temperature differences. The lower differences are those of direct evaporative cooling and the higher differences involve the desiccant mode. The efficiency of the heat recovery wheel is constant independently of the temperature difference and is always higher than 0.7. 
Am. J. Environ. Sci., 7 (3): 207-211, 2011

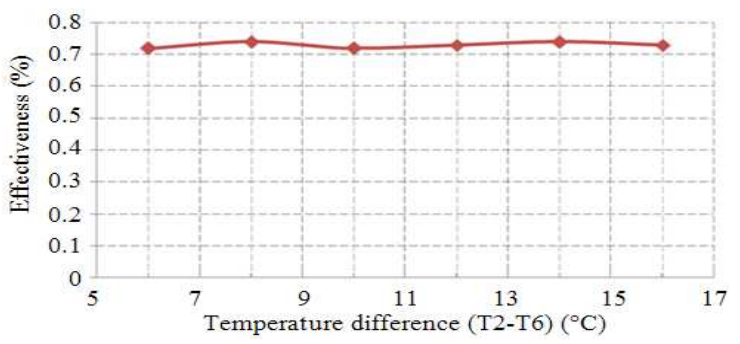

Fig. 5: Efficiency of the sensible heat recovery wheel

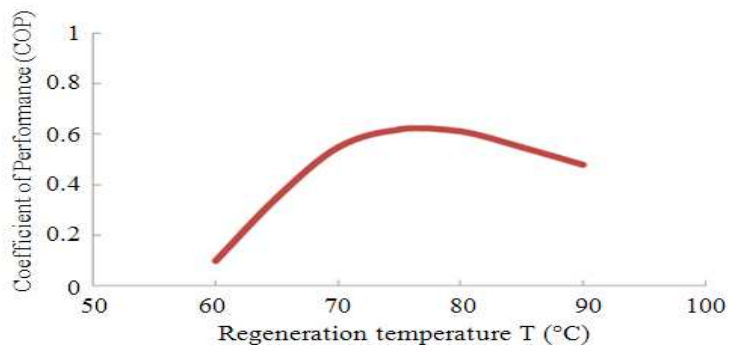

Fig. 6: Effect of regeneration temperature, coefficient of performance

This result is predictable since efficiency does not vary significantly with the conductance unless there are important heat losses which is not the case here. This efficiency of 0.7 is crucial for desiccant cooling system (Bourdoukan et al., 2008).

Figure 6, shows the change of COP with respect to different regeneration temperature. It can be found that; COP could obtain a maximum when $T_{r}$ is between 70 and $80^{\circ} \mathrm{C}$. The influence of the increment of regeneration heat is much more significant, which leads COP to drops off.

Based on these results, to achieve a tradeoff between the system energy performance (COP) and the supply air condition, regeneration temperature between 65 and $80^{\circ} \mathrm{C}$ is more reasonable for the system operation under hot and humid climatic condition.

\section{DISCUSSION}

A desiccant-based evaporative cooling system offers a promising alternative to conventional airconditioning systems for climates with high latent load (humid climates). The experiments carried out in the test described here showed that such a system has significant potential for reducing the uncomfortably indoor humidity levels that tend to occur in summer certain regions.
In experiments areas with relatively low sensible heat ratios (humid climates) the desiccant system is expected to be more effective at maintaining comfortable humidity levels than the conventional air conditioning system. In areas with high sensible heat ratios (dry climates) the use of the desiccant system with indirect evaporative coolers can potentially increase the total number of hours of discomfort.

\section{CONCLUSION}

In this study, the impact of outside conditions and of the efficiency of key components (desiccant wheel and heat recovery wheel) on the supply conditions of a desiccant system has been investigated for solar assisted desiccant cooling system.

The main findings can be summarized as:

- Required regeneration temperature of desiccant cooling system is much lower, hence low-grade energy such as solar energy and waste heat can be efficiently utilized and operating cost can be significantly reduced. High $\mathrm{COP}_{\mathrm{th}}$ of the system can be achieved under the lower regeneration temperature

- Solar assisted desiccant cooling system could provide satisfied supply air not only under mild ARI condition but also under extreme weather condition with much higher temperature and humidity ratio when regenration temperatures are higher than $60,70,80$ and $90^{\circ} \mathrm{C}$, respectively. To achieve a tradeoff between the supply air state and system energy performance, regeneration temperatures $75^{\circ} \mathrm{C}$ are recommended under these condition. $\mathrm{COP}_{\text {th }}$ of the system is almost higher

- Under given conditions, the increase in inlet humidity of process air results in obvious increase of moisture removal as well as COP. Lower inlet temperature and humidity ratio of regeneration air lead to better system performance

In the desiccant system with two wheels it was observed clearly that the performance of the system depends on the individual performance of each component of the system that is proven in the numerical validation and the experimental validation. However, discrepancies are observed that can be associates to the uncertainties of the used variable and estimates of variable not supplied. It is observed that a desiccant system the two wheels do not provide thermal comfort for tested region, being necessary a configuration with three or four wheels. 


\section{REFERENCES}

Ibrahim, A., G.L. Jin, R. Daghigh, M.H.M. Salleh and M.Y. Othman et al., 2009. Hybrid Photovoltaic Thermal (PV/T) air and water based solar collectors suitable for building integrated applications. Am. J. Environ. Sci., 5: 618-624. DOI: 10.3844/ajessp.2009.618.624

Ando, K. and A. Kodama, 2005. Experimental study on a process design for adsorption desiccant cooling driven with a low-temperature heat. Adsorption, 11: 631-636. DOI: 10.1007/s10450-005-5997-1

Bourdoukan, P., E. Wurtz, P. Joubert and M. Sperandio, 2008. Potential of solar heat pipe vacuum collectors in the desiccant cooling process: Modeling and experimental results. Solar Energy, 82: 1209-1219.

DOI: 10.1016/J.SOLENER.2008.06.003

Camargo, J.R. and C.D. Ebinuma, 2005. An evaporative and desiccant cooling system for air conditioning in humid climates. J. Braz. Soc. Mech. Sci. Eng., 27: 243-247. DOI:
Charoensawan, P. and C. Wannagosit, 2010. Computational study of hybrid water heater with evacuated glass tube solar collector and rice husk combustion. Energy Res. J., 1: 182-188. DOI: 10.3844/erjsp.2010.182.188

Dammak, N., B. Chaouachi, S. Gabsi and M. Bourouis, 2010. Optimization of the geometrical parameters of a solar bubble pump for absorption-diffusion cooling systems. Am. J. Eng. Applied Sci., 3: 693698. DOI: 10.3844/ajeassp.2010.693.698

Jain, S. and P.L. Dhar, 1995. Evaluation of solid desiccant-based evaporative cooling cycles for typical hot and humid climates. Int. J. Refrig., 18: 287-296. DOI: 10.1016/0140-7007(95)00016-5

Kairouani, L. and E. Nehdi, 2005. Thermodynamic analysis of an absorption/compression refrigeration system using geothermal energy. Am. J. Applied Sci.,2: 914-919. DOI: 10.3844/ajassp.2005.914.919

Rachman, A., S. Mat, T. Iskandar, M. Yahya and A. Zaharim et al., 2010. Solar air conditioning system using desiccant wheel technology. Proceedings of the 9th WSEAS International Conference on System science and Simulation in Engineering, Stevens Point, Wisconsin, USA., Japan, pp: 419423. ISBN: 978-960-474-230-1 